\title{
Independence of EPR and PAP tests performed on resistance spot welding joints
}

\author{
Virginia Ahedo ${ }^{a, *}$, Óscar Martín ${ }^{b}$, José Ignacio Santos ${ }^{c}$, Pilar De Tiedra ${ }^{d}$, José Manuel Galán \\ a CaSEs - Complexity and socioecological systems, Depto. Arqueología y Antropología. Institución Milá y \\ Fontanals - Consejo Superior de Investigaciones Cientificas. C/ Egipcíaques, 15. 08001 Barcelona, \\ Spain. \\ b Ingeniería de los Procesos de Fabricación, Departamento CMeIM/EGI/ICGF/IM/IPF, Universidad de \\ Valladolid, Escuela de Ingenierías Industriales, Paseo del Cauce 59, Valladolid 47011, Spain. \\ c INSISOC, Área de Organización de Empresas, Departamento de Ingeniería Civil, Escuela Politécnica \\ Superior, Universidad de Burgos, Edificio La Milanera, C/Villadiego S/N, Burgos 09001, Spain. \\ d Ciencia de los Materiales e Ingeniería Metalúrgica, Departamento CMeIM/EGI/ICGF/IM/IPF, \\ Universidad de Valladolid, Escuela de Ingenierías Industriales, Paseo del Cauce 59, Valladolid 47011, \\ Spain. \\ * Corresponding author. Ph.: +34-934423489, Fax: +34-934430071, E-mail: v.ahedo@imf.csic.es (V. \\ Ahedo)
}

\section{Abstract}

In the present paper, the possible relationships among the variables of the potentiodynamic anodic polarization (PAP) test and the electrochemical potentiokinetic reactivation (EPR) test, both performed on resistance spot welding joints of AISI 304 stainless steel, are investigated. Results show that PAP variables are statistically independent from those of EPR, which implies independence between the pitting corrosion behavior and the degree of sensitization of the material. Parameters from PAP test are dependent among them, but this association is found noisy since the current density along the passive zone is not exactly constant. The parameters from the EPR test are confirmed as very related, presenting a linear relationship and a high coefficient of determination.

Keywords: Resistance spot welding; AISI 304 stainless steel; Pitting potential; Reactivation charge; Electrochemical potentiokinetic reactivation test; Potentiodynamic anodic polarization test; Maximal Information Coefficient; Distance correlation. 


\section{Introduction}

Resistance Spot Welding (RSW) is a joining process extensively used for the fabrication of sheet metal assemblies because of its excellent techno-economic benefits such as low cost, simplicity, high speed and suitability for automation ${ }^{1}$. Stainless steel (SS) sheets are increasingly used due to their high corrosion resistance, beautiful appearance and reasonable weldability ${ }^{2}$. Austenitic SS constitutes the largest stainless family in terms of alloy type and usage, being especially suitable when an excellent combination of strength and corrosion resistance in aqueous solutions at ambient temperature is required ${ }^{2}$. Thus, RSW of austenitic SS sheets is frequently used and applied to transportation vessels, kitchen furniture and utensils and building applications ${ }^{3,4}$.

Pitting corrosion is a type of localized corrosion, which, in austenitic SS, is directly affected by the microstructural transformations caused by the thermal energy associated with the welding process 5,6 . Pitting corrosion behavior can be assessed from the $E_{\text {pit }} 7,8$, obtained in the potentiodynamic anodic polarization (PAP) test.

Sensitization is a phenomenon caused by the heat generated in the welding process of austenitic SSs, which gives rise to precipitation of chromium rich phases ${ }^{9-12}$ along critical zones; since chromium is responsible for the corrosion resistance, because it permits the formation of the passive layer (a protective film based on chromium oxide) on the steel surface ${ }^{13,14}$, the chromium depleted zones adjacent to the chromium rich phases are more susceptible to corrosion attack. The degree of sensitization (DOS) may be evaluated from the reactivation charge $Q_{r}{ }^{15,16}$, obtained in the electrochemical potentiokinetic reactivation (EPR) test.

Mudali et al. ${ }^{17}$ demonstrated that the pitting corrosion resistance of austenitic SSs decreased as the DOS increased, which was attributed to the formation of a heterogeneous microstructure consisting of chromium rich $\mathrm{M}_{23} \mathrm{C}_{6}$ carbides, chromium depleted regions and the carbide/matrix interfaces resulting from the sensitizing treatment. EPR has been primarily used to assess the DOS in austenitic SSs ${ }^{14,18}$; nevertheless, as indicated by Prohaska et al. ${ }^{19}$, it can also provide information on the general corrosion behavior. According to Číhal and Štefec ${ }^{20}$, the EPR method is particularly well suited to determine the susceptibility of austenitic SSs to intergranular corrosion and it can also assist in studies of other forms of localized corrosion such as pitting corrosion. Wu et al. ${ }^{21}$ demonstrated that, for sensitized Alloy 600 (a nickel base alloy), the reactivation hump of the EPR curve includes both the intergranular corrosion effect and the pitting corrosion effect; on the contrary, as pointed out by $\mathrm{Wu}$ and Tsai ${ }^{22}$, these results differ significantly from those obtained in SS, where the reactivation hump of the EPR curve merely corresponds to intergranular corrosion in sensitized AISI 304 SS.

The aim of the present work is to explore if there exists some kind of relationship among any of the variables of the PAP and EPR tests performed on RSW joints of AISI 304 SS. For that purpose, advanced statistical and computational analysis techniques were implemented, some of which had already been successfully applied to the study of corrosion phenomena ${ }^{23-25}$. 
This paper uses a multi-methodological approach to overcome the shortcomings that each technique presents when used in an isolated manner.

The analysis is performed on three stages: Initially, multiple linear regression is employed to identify any possible linear relationships between the tests. The problem with linear regression is that it only seeks linear relationships even though the absence of a linear pattern does not imply the nonexistence of other types of relations. Subsequently, some of the most relevant non-linear regression algorithms ${ }^{26,27}$ are implemented to verify if non-linear relationships appear. Finally, to confirm the results obtained on the previous stages, the three most wellknown advanced bivariate dependence measures, i.e., MIC, dCor and HHG are applied to the data. The rationale behind the use of these methods instead of other statistical measures such Pearson's correlation coefficient lies in their ability to identify a wide range of associations among variables, not limited to linear or functional patterns ${ }^{28}$. Comparisons of the performance of the three bivariate dependence measures in terms of statistical power or range of associations are not yet conclusive ${ }^{29-33}$, and hence the three have been used to increase the robustness of the results.

The conducted exploratory analysis is relevant since it sheds light on the controversy of whether the parameters of the PAP and EPR tests are related or not, and, thus, allows optimizing and shortening the assessment of the in-service performance of the RSW joints of AISI 304 SS.

\section{Experimental Procedure}

\subsection{Materials and equipment}

The chemical composition and the mechanical properties of the AISI 304 austenitic SS sheets welded by RSW are shown in Tables 1 and 2 respectively. The sheet thickness was $0.8 \mathrm{~mm}$.

Table 1. Chemical composition of the AISI 304 austenitic SS sheets (wt. \%).

\begin{tabular}{cccccccc}
\hline $\mathrm{C}$ & $\mathrm{Cr}$ & $\mathrm{Ni}$ & $\mathrm{Si}$ & $\mathrm{Mn}$ & $\mathrm{Mo}$ & $\mathrm{Al}$ & $\mathrm{Co}$ \\
\hline 0.08 & 18.03 & 8.74 & 0.426 & 1.153 & 0.36 & 0.003 & 0.17 \\
\hline $\mathrm{Cu}$ & $\mathrm{Nb}$ & $\mathrm{Ti}$ & $\mathrm{V}$ & $\mathrm{W}$ & $\mathrm{S}$ & $\mathrm{P}$ & $\mathrm{Fe}$ \\
\hline 0.39 & 0.02 & 0.004 & 0.05 & 0.03 & 0.002 & 0.019 & Bal. \\
\hline
\end{tabular}

Table 2. Mechanical properties of the AISI 304 austenitic SS sheets.

\begin{tabular}{cccc}
\hline $\begin{array}{c}\text { Yield strength } \\
(\mathrm{MPa})\end{array}$ & Tensile strength & Total elongation & Microhardness \\
$(\mathrm{MPa})$ & $(\%)$ & $(\mathrm{HV}, 100 \mathrm{~g})$ \\
\hline
\end{tabular}




\begin{tabular}{llcc}
\hline 290 & 675 & 70 & 162 \\
\hline
\end{tabular}

The parent metal has an austenitic structure with $\delta$-ferrite bands clearly oriented in the rolling direction as a result of prior cold work (Fig. 1).

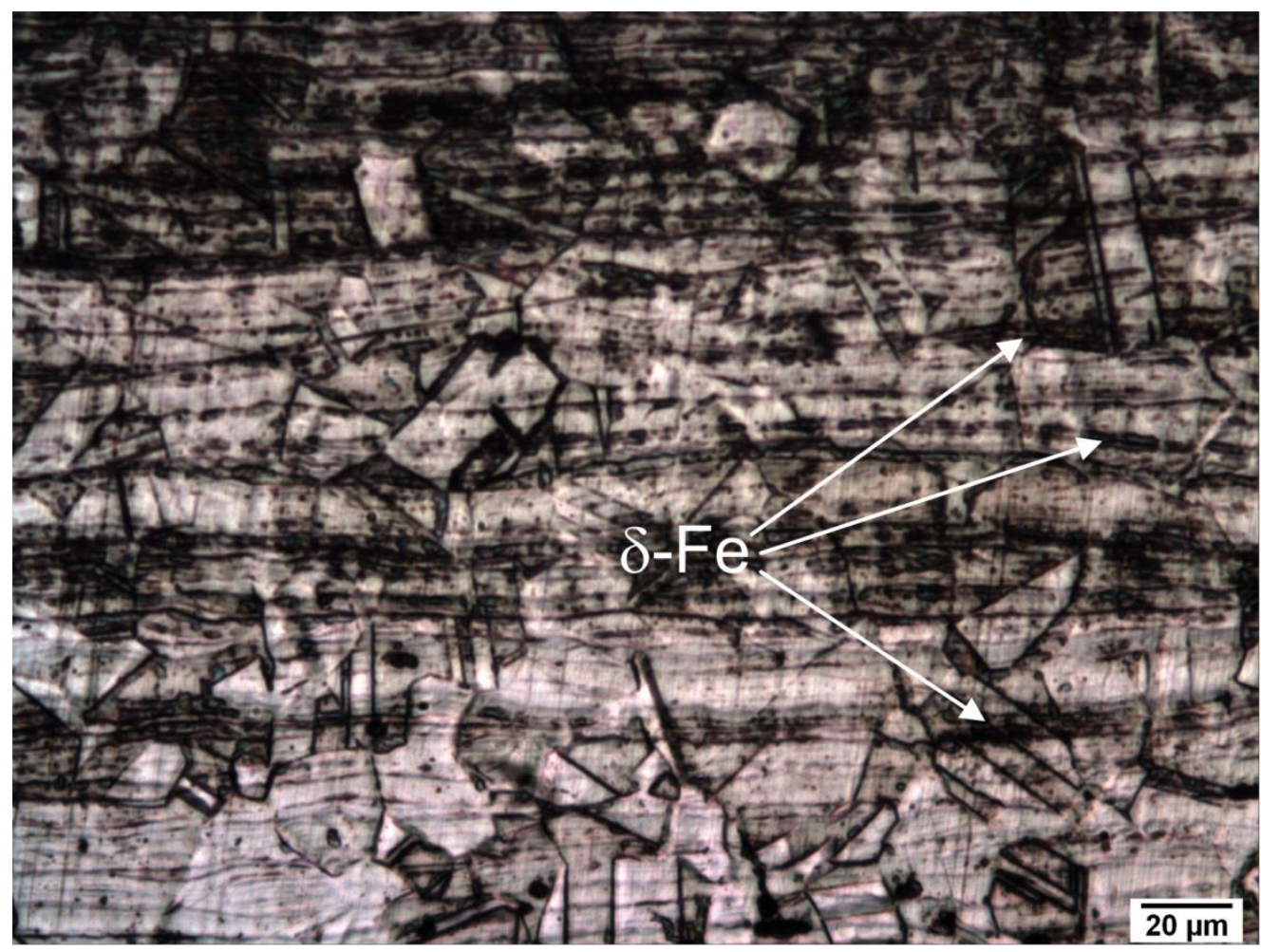

Fig. 1. Micrograph of a longitudinal section of the parent metal, that shows an austenitic structure with $\delta$-ferrite bands clearly oriented in the rolling direction as a result of prior cold work. Electrolytic etching with oxalic acid according to ASTM A 262-91 Practice A ${ }^{34}$.

\subsection{RSW process}

The AISI 304 austenitic SS sheets were welded in a single-phase alternating current (AC) $50 \mathrm{~Hz}$ equipment by using water-cooled truncated cone RWMA Group A Class 2 electrodes with 16 $\mathrm{mm}$ body diameter and $4.5 \mathrm{~mm}$ face diameter.

The controlled parameters in the RSW process were: (i) WT that varied from 12 to 2 cycles, with a 1 cycle step decrease; (ii) WC that varied approximately from 6.5 to $1.5 \mathrm{kA}$ RMS with a 0.5 kA RMS step decrease; and (iii) EF that took two values: 1000 and $1500 \mathrm{~N}$. These three parameters are, according to Aslanlar ${ }^{35}$ and to Pouranvari and Marashi ${ }^{36}$, the most important welding parameters in RSW.

Thus, there were 242 , i.e. $11 \times 11 \times 2$, different welding conditions and a RSW joint was obtained for each of these 242 welding conditions. 


\subsection{Microstructure of the RSW joint}

The thermal energy associated with the RSW process gives rise to the formation of two new zones from the parent metal (Fig. 2): (i) the weld nugget ${ }^{37-39}$, formed from the solidification of the molten metal ${ }^{40}$, with a cast dendritic microstructure of austenite with a high content of $\delta$ ferrite in interdendritic regions as a consequence of the rapid cooling ${ }^{14,41-43}$ (Fig. 3); and (ii) the heat affected zone (HAZ), adjacent to the weld nugget, where the sensitization phenomenon may occur.

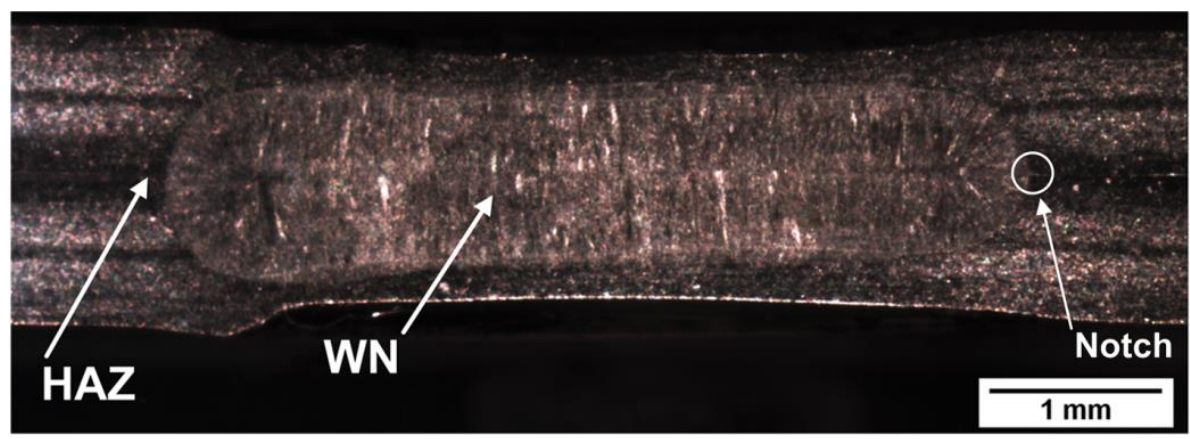

Fig. 2. Macrograph of a cross-sectioned RSW joint that shows the weld nugget (WN) and the HAZ. Electrolytic etching with oxalic acid according to ASTM A 262-91 Practice A ${ }^{34}$.

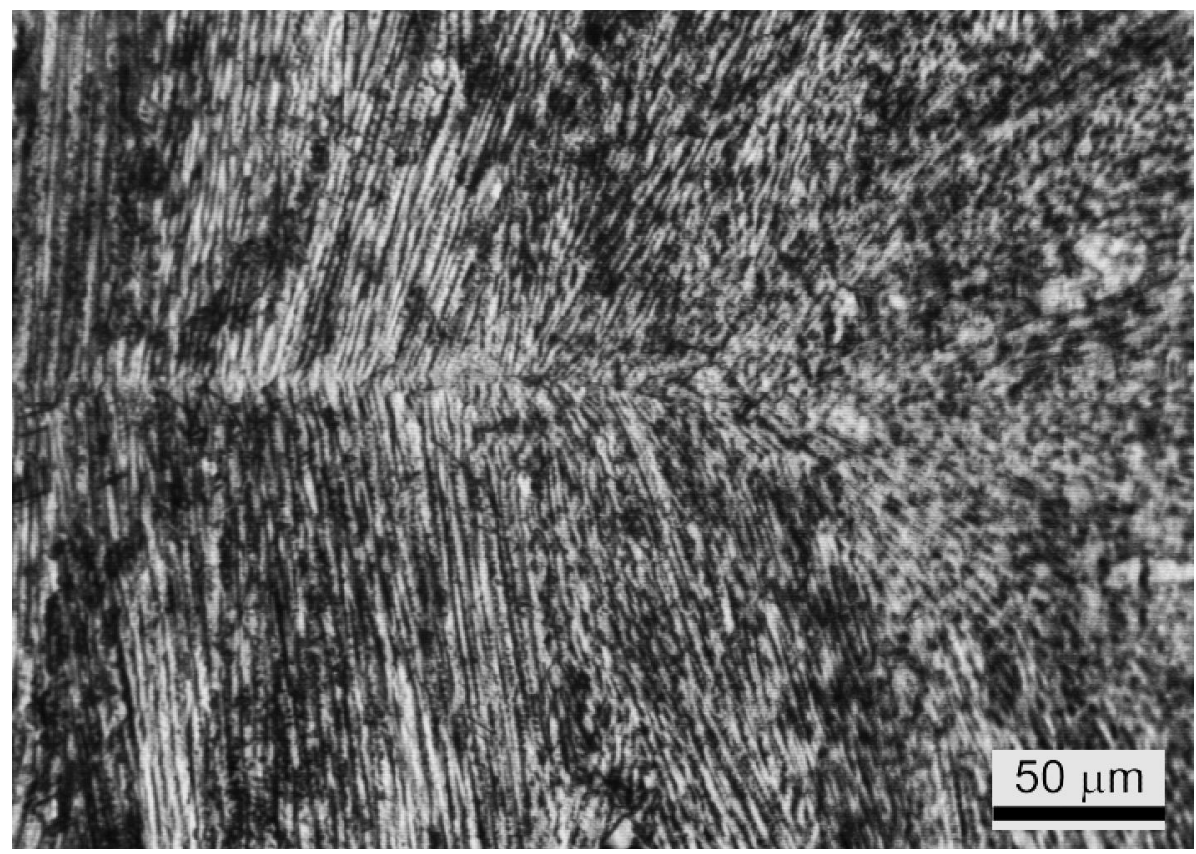

Fig. 3. Micrograph of the weld nugget that shows the cast dendritic microstructure of austenite with $\delta$-ferrite in interdendritic regions. Electrolytic etching with oxalic acid according to ASTM A 262-91 Practice A ${ }^{34}$.

These microstructural transformations associated with the RSW process have influence on the: 
- Pitting corrosion behaviour, because $\delta$-ferrite has a deleterious effect on the pitting corrosion behaviour, which was attributed by Pan et al. ${ }^{44}$ to the galvanic effect existing between austenite phase and $\delta$-ferrite, and by Pujar et al. ${ }^{45}$ to the fact that the higher the $\delta$-ferrite content, the lower the stability of the passive film.

- DOS, where the type of sensitization depends on the zone where the precipitation of chromium rich phases occurs ${ }^{14,18}$ : (i) interdendritic corrosion (located in the weld nugget), which is associated with dendritic boundaries that have a high content of $\delta$ ferrite (Fig. 3); (ii) transgranular corrosion (located in the HAZ), which is associated with austenite/ $\delta$-ferrite interfaces, twins and slip bands inside austenitic grains (Fig. 4); and (iii) intergranular corrosion (located in the HAZ), which is associated with grain boundaries (Fig. 4).

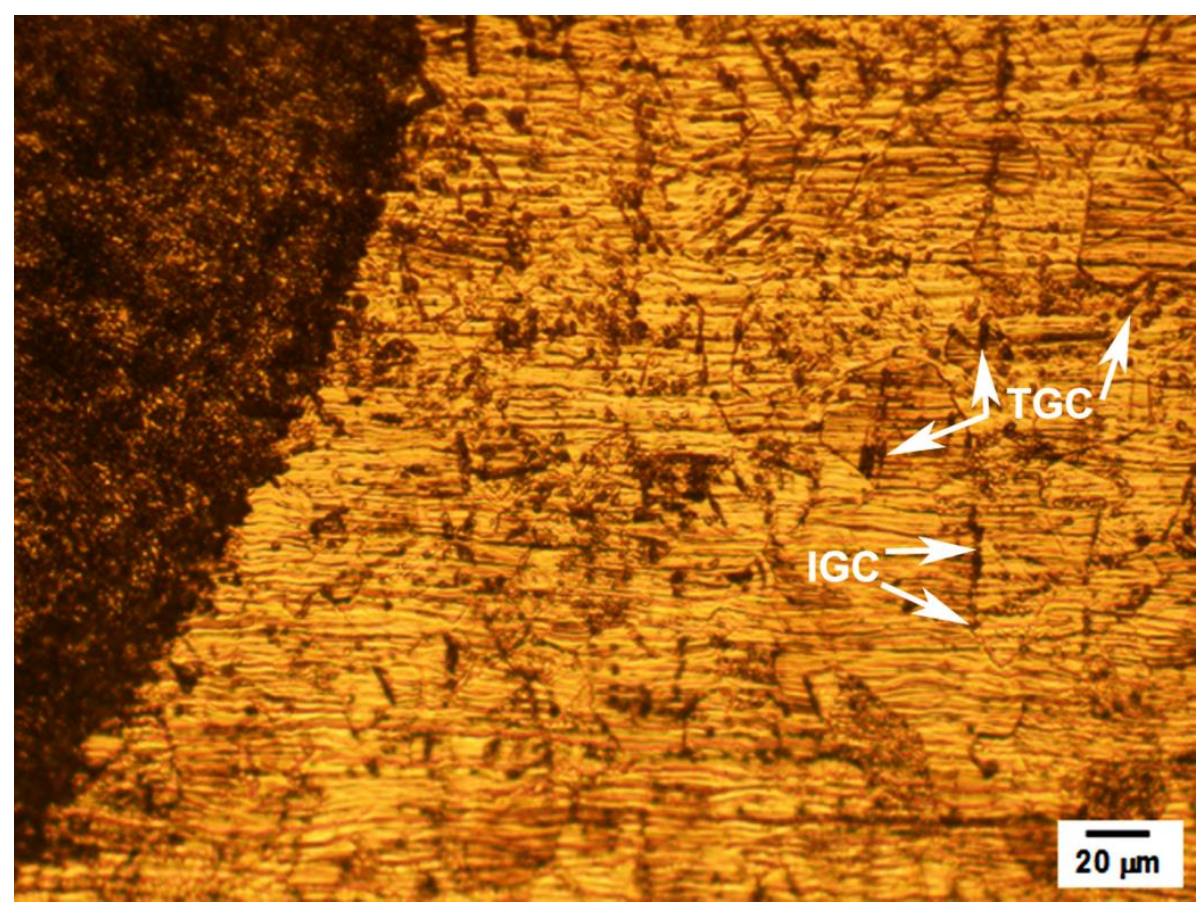

Fig. 4. Micrograph of the HAZ, adjacent to the weld nugget (left), which shows: (i) transgranular corrosion (TGC) inside austenitic grains; and (ii) intergranular corrosion (IGC) associated with grain boundaries. Micrograph taken after EPR test.

\subsection{PAP tests}

PAP is a quasi non-destructive technique that provides information about pitting corrosion behavior of austenitic stainless steels ${ }^{46,47}$. PAP tests were performed on the 242 RSW joints, according to ASTM G5-94 (Reapproved 1999) ${ }^{48}$, by using a large-scale electrochemical cell which has two high-purity carbon auxiliary (counter) electrodes and a saturated calomel electrode (SCE) positioned in front of the specimen at a distance of $4 \mathrm{~mm}^{49}$. 
The tests were carried out in acid solution with chlorides containing $1 \mathrm{~N} \mathrm{H}_{2} \mathrm{SO}_{4}+0.5 \mathrm{~N} \mathrm{NaCl}$ at a temperature of $30^{\circ} \mathrm{C} \pm 1$. The experimental procedure of the tests was the following: $5 \mathrm{~min}$ delay at open circuit potential $\left(\mathrm{V}_{\mathrm{OC}}\right), 2 \mathrm{~min}$ anodic attack at $-220 \mathrm{mV} \mathrm{V}_{S C E}$, then a delay of $3 \mathrm{~min}$ at VOC, 2 min cathodic cleaning at $-600 \mathrm{mV}_{\mathrm{SCE}}, 3 \mathrm{~min}$ delay at $\mathrm{V}_{\mathrm{OC}}$ and then anodic potentiodynamic scan that starts at $50 \mathrm{mV}_{\text {SCE }}$ below $V_{\text {OC }}$ until $1000 \mathrm{mV}_{\text {SCE. }}$. The potential scan rate was $50 \mathrm{mV} / \mathrm{min}$.

Pitting corrosion behavior was assessed from the $E_{\text {pit, }}$ obtained from the PAP curve (Fig 5). The higher the $E_{\text {pit }}$, the higher the pitting resistance ${ }^{50,51}$. The peak active current density lact and the passive current density $I_{\text {pas }}$ were also considered (Fig. 5).

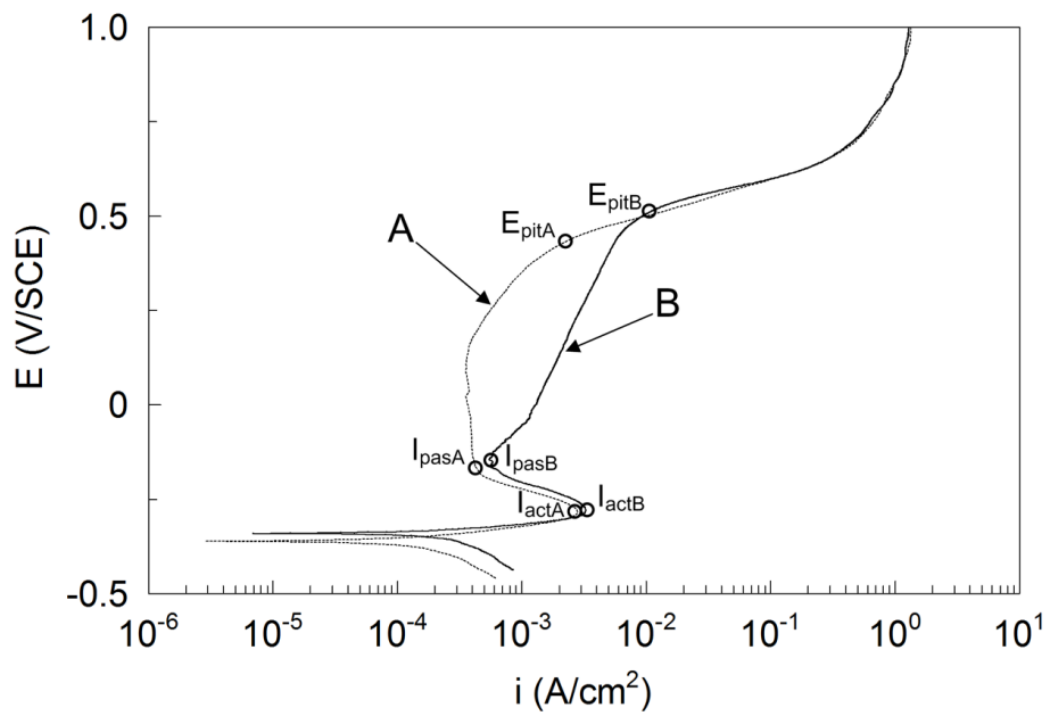

Fig. 5. PAP curves of: (A) RSW joint obtained with $W T=9$ cycles, $W C=6.42 \mathrm{kA} R M S, E F=1000 \mathrm{~N}$; and (B) RSW joint obtained with $\mathrm{WT}=11 \mathrm{cycles}, \mathrm{WC}=6.56 \mathrm{kA} \mathrm{RMS}, \mathrm{EF}=1000 \mathrm{~N}$.

\subsection{EPR tests}

EPR is a quasi non-destructive test that is much quicker, more sensitive and more accurate than the conventional corrosion tests ${ }^{19}$ and that is extensively used to assess the DOS in austenitic SSs ${ }^{20}$. EPR tests were performed on the 242 RSW joints, by using a large-scale electrochemical cell which has two high-purity carbon auxiliary (counter) electrodes and a saturated calomel electrode (SCE) positioned in front of the specimen at a distance of $4 \mathrm{~mm}{ }^{52}$, according to ASTM Standard G108-92 ${ }^{53}$ with the electrolyte composition modification proposed by De Tiedra et al. ${ }^{14}$; this modification counteracted the adverse notch effect (the RSW joint has a notch (Fig. 2), more or less pronounced depending on heat input and electrode force ${ }^{23}$, through which the electrolyte may seep, changing EPR test results ${ }^{14}$ ).

The tests were carried out at a temperature of $30{ }^{\circ} \mathrm{C} \pm 1$ out and the electrolyte was $0.5 \mathrm{M}$ $\mathrm{H}_{2} \mathrm{SO}_{4}+0.03 \mathrm{M} \mathrm{KSCN}$. The experimental procedure of the test was the following: a delay of 5 
min at $V_{O C}$, deaerated, an anodic attack at $-220 \mathrm{mV} \mathrm{SCE}_{S \mathrm{C}}$ for $2 \mathrm{~min}$, a delay of $2 \mathrm{~min}$ at $\mathrm{V}_{\mathrm{OC}}$, a cathodic cleaning at $-600 \mathrm{mV}_{\text {SCE }}$ for $1 \mathrm{~min}$ and a delay of $5 \mathrm{~min}$ at $\mathrm{V}_{\mathrm{OC}}$. Passivation was accomplished by applying $200 \mathrm{mV}_{\mathrm{SCE}}$ for $2 \mathrm{~min}$. The reactivation scan started at $200 \mathrm{mV}$ until 50 $\mathrm{mV}$ below the $V_{o c}$ at a rate of $100 \mathrm{mV} / \mathrm{min}$.

The DOS was evaluated from the reactivation charge $Q_{r}$, which is the area under the reactivation hump of the EPR curve (Fig. 6). The higher the $Q_{r}$, the higher the DOS. The maximum reactivation current density $I_{r}$ was also considered.

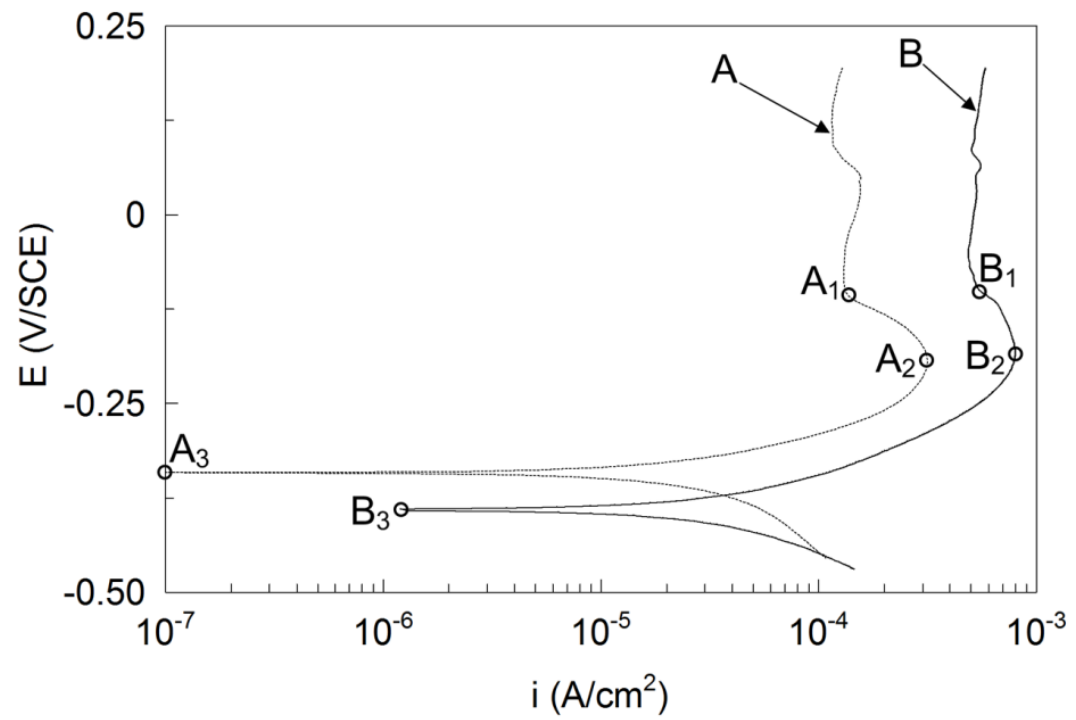

Fig. 6. EPR curves of: (A) RSW joint obtained with $W T=2$ cycles, $W C=4.06 \mathrm{kA} R M S, E F=1500 \mathrm{~N}$; and (B) RSW joint obtained with WT $=6$ cycles, $W C=5.64 \mathrm{kA} R M S, E F=1500 \mathrm{~N}$. $Q_{r A}$ is the area under $A_{1}-A_{2}-A_{3}$ and $Q_{r B}$ is the area under $B_{1}-B_{2}-B_{3}$. I $I_{A}$ corresponds to $A_{2}$ and $I_{r B}$ corresponds to $B_{2}$.

\section{Computational analysis}

First of all, it is important to remind that the variables from the PAP test are the peak active current density $I_{\text {act }}\left(A / \mathrm{cm}^{2}\right)$, the passive current density $I_{\text {pas }}\left(A / \mathrm{cm}^{2}\right)$ and the pitting potential $E_{\text {pit }}$ $\left(V_{S C E}\right)$, while those from the EPR test are the reactivation current density $I_{r}\left(A / \mathrm{cm}^{2}\right)$ and the reactivation charge $Q_{r}\left(C / \mathrm{cm}^{2}\right)$.

To initially analyze the possible relationships among the variables of both tests performed on RSW joints of AISI 304 SS, a complete set of basic multivariate linear regressions was conducted (see

Table 3). In each multivariate linear regression, one of the outputs of a test was used as dependent variable, while all the outputs of the complementary test were used as explanatory regressors. These analyses provided two relevant indicators about the independence of the variables. The first is the $\mathrm{R}^{2}$ statistic -the percentage of the dependent variable variation that is explained by the fitted linear model-. The second is the F-test of the overall significance of the model, which compares the fitted model to a model with no regressors, assuming as null hypothesis that both models are equal. The results show that $R^{2}$ is small in all the cases, suggesting very weak or absence of linear dependence. At the same time, the F-test indicates 
that the null hypothesis cannot be rejected for the standard significance level $(p<0.05)$, i.e., the fitted models are not statistically better than the prediction of the average.

Table 3. $R^{2}$, F-test value and $p$-value of the different multivariate linear analysis.

\begin{tabular}{ccccc}
\hline Predicted & Regressors & $\mathrm{R}^{2}$ & $\mathrm{~F}$ value & $\mathrm{p}$-value \\
\hline $\mathrm{I}_{\mathrm{r}}$ & $\mathrm{I}_{\text {act }}+\mathrm{I}_{\text {pas }}+\mathrm{E}_{\text {pit }}$ & 0.0105 & 0.8418 & 0.4722 \\
$\mathrm{Q}_{\mathrm{r}}$ & $\mathrm{I}_{\text {act }}+\mathrm{I}_{\text {pas }}+\mathrm{E}_{\text {pit }}$ & 0.0056 & 0.4483 & 0.7187 \\
$\mathrm{I}_{\text {act }}$ & $\mathrm{I}_{\mathrm{r}}+\mathrm{Q}_{\mathrm{r}}$ & 0.0209 & 2.5460 & 0.0805 \\
$\mathrm{I}_{\text {pas }}$ & $\mathrm{I}_{\mathrm{r}}+\mathrm{Q}_{\mathrm{r}}$ & $5.099 \mathrm{e}-05$ & 0.0061 & 0.9939 \\
$\mathrm{E}_{\text {pit }}$ & $\mathrm{I}_{\mathrm{r}}+\mathrm{Q}_{\mathrm{r}}$ & 0.0040 & 0.4793 & 0.6198 \\
\hline
\end{tabular}

However, as pointed in the introduction, the absence of a linear relation does not univocally mean independence between the variables of both tests. It could be the case that there exists a non-linear dependence not detected by the multivariate linear regression technique. To verify this assumption, some of the most relevant non-linear regression algorithms ${ }^{26,27}$ such as Neural Networks ${ }^{54}$, Support Vector Machines for Regression ${ }^{55}$, Random Forests ${ }^{56}$ and Stochastic Gradient Boosting ${ }^{57}$ were fitted and compared with the average prediction using an ANOVA test (Table 4). Again, each output of a test was taken as predicted variable using the outputs of the other test as predictors. The performance of each algorithm was calculated using 10-fold nested cross-validation. Results show that there is no statistical difference among any of the non-linear algorithms and the average prediction, which strongly suggests statistical independence between the PAP and EPR tests.

Table 4. ANOVA test of several non-linear regression algorithms and mean prediction. For each fitted model, the average root squared error of the prediction and the standard deviation (in brackets) are provided.

\begin{tabular}{ccccccc}
\hline & \multicolumn{7}{c}{ Algorithm } \\
\cline { 2 - 6 } Predicted & $\begin{array}{c}\text { Neural } \\
\text { network }\end{array}$ & $\begin{array}{c}\text { Support } \\
\text { Vector } \\
\text { Machine }\end{array}$ & $\begin{array}{c}\text { Stochastic } \\
\text { Gradient } \\
\text { Boosting }\end{array}$ & $\begin{array}{c}\text { Random } \\
\text { Forest }\end{array}$ & Mean & $\begin{array}{c}\text { ANOVA } \\
(p \text {-value) }\end{array}$ \\
\hline $\mathrm{I}_{\mathrm{r}}$ & 0.00193 & 0.00188 & 0.00185 & 0.00208 & 0.00185 & 0.994 \\
& $(0.00126)$ & $(0.00128)$ & $(0.00122)$ & $(0.00122)$ & $(0.00125)$ & \\
$\mathrm{Q}_{r}$ & 0.206 & 0.204 & 0.200 & 0.217 & 0.198 & 0.997 \\
& $(0.122)$ & $(0.124)$ & $(0.118)$ & $(0.115)$ & $(0.120)$ & \\
$\mathrm{I}_{\text {act }}$ & 0.000968 & 0.000945 & 0.000929 & 0.000974 & 0.000929 & 0.941 \\
& $(0.000156)$ & $(0.000174)$ & $(0.000149)$ & $(0.000143)$ & $(0.000150)$ & \\
$I_{\text {pas }}$ & 0.000151 & 0.000147 & 0.000142 & 0.000142 & 0.000142 & 0.994 \\
& $(4.95 \mathrm{e}-05)$ & $(5.71 \mathrm{e}-05)$ & $(5.11 \mathrm{e}-05)$ & $(5.11 \mathrm{e}-05)$ & $(5.10 \mathrm{e}-05)$ & \\
$\mathrm{E}_{\text {pit }}$ & 0.0375 & 0.0368 & 0.0373 & 0.0420 & 0.0368 & 0.947 \\
& $(0.0161)$ & $(0.0163)$ & $(0.0163)$ & $(0.0179)$ & $(0.0166)$ & \\
\hline
\end{tabular}

To confirm the independence between PAP and EPR tests some bivariate dependence measures were calculated. In particular, those based on the concepts of rank correlation and information theory, since they are conceived to detect non-linear and non-functional relationships ${ }^{28}$. Concretely, the present work explores the possible relationships using distance correlation (dCor) ${ }^{58}$, Heller-Heller-Gorfine (HHG) measure ${ }^{59}$ and maximal information coefficient (MIC) ${ }^{60}$, where MIC and dCor focus mainly on assessing the intensity and noise of the possible relationships, while the HHG test determines if the relationship is statistically significant. 
MIC is a recent and increasingly popular metric conceived for two-dimensional data that is based on binning, i.e., on partitioning data in different intervals, to obtain the grid necessary to estimate the data probability distribution required to calculate the mutual information (MI) statistic.

$\mathrm{MI}$ is computed for each pair $(x, y)$ on different grids, exploring grids up to a maximal resolution. Then, maximal values obtained for each pair $(x, y)$ are normalized and saved in the characteristic matrix $M$. MIC happens to be the maximum value in $M$.

MIC's popularity is based on two important heuristic properties it is said to have: (i) generality -the measure captures a wide range of associations, not limited to specific function types- and (ii) equitability - the statistic gives similar scores to equally noisy relationships of different types-. Nevertheless, this assertion and the comparison of the MIC with alternative dependence measures happen to be controversial ${ }^{29-33}$, especially in terms of statistical power in the case of small sample sizes (less than 100). Consequently, the use of alternative measures such as distance correlation (dCor) ${ }^{58}$ and HHG ${ }^{59}$ metrics is suggested.

Distance correlation is based on the concept of energy distances and it is calculated by dividing the distance covariance between the two variables $X$ and $Y$ by the product of their distance standard deviations. In the same way as MIC, its value ranges from 0 to 1 , where 0 is obtained in the case of independence and 1 in the case of a noiseless perfect dependence.

The HHG test is motivated by the notion that if $X$ and $Y$ are dependent and have a continuous joint density, then there exists a point $\left(x_{0}, y_{0}\right)$ in the sample space of $(X, Y)$ and radii $R_{x_{0}}$ and $R_{y_{0}}$ around $x_{0}$ and $y_{0}$ respectively, such that the joint distribution of $X$ and $Y$ differs from the product of the marginal distributions, i.e., $H_{1}: F_{X Y} \neq F_{X} F_{Y}$, with the null hypothesis of independence: $H_{0}: F_{X Y}=F_{X} F_{Y}$. The HHG test is usually analyzed by means of the $p$-value.

Given the fact that the number of samples of the database recorded for this work is above 100 , which is the value where MIC's statistical power problems were said to appear, MIC is an appropriate measure for the present case study and has been computed using the ChiMIC algorithm ${ }^{61}$. Nonetheless, the three dependence measures -MIC, dCor and HHG- were implemented to obtain more precise conclusions and to test the robustness of the results with respect to the chosen measure. Table 5 presents a summary of the results obtained for the MIC, dCor and HHG in that order.

Table 5. Results of the bivariate dependence analysis by means of the MIC, dCor and the p-value obtained with the HHG test. MIC and dCor statistics indicate strong association when close to 1 while lower values may show noisy relations. HHG (in brackets) consider as null hypothesis independence between two variables. In the table relationships found at a significance level of 0.01 are shown in bold numbers.

\begin{tabular}{cccccc}
\hline & $\mathrm{Q}_{r}$ & $\mathrm{I}_{\mathrm{r}}$ & $\mathrm{l}_{\text {act }}$ & $\mathrm{I}_{\text {pas }}$ & $\mathrm{E}_{\text {pit }}$ \\
\hline $\mathrm{Q}_{\mathrm{r}}$ & 1.0000 & 0.9580 & 0.1473 & 0.1645 & 0.1872 \\
& 1.0000 & 0.9700 & 0.1090 & 0.0919 & 0.0908 \\
& $\mathbf{( 0 . 0 0 1 )}$ & $\mathbf{( 0 . 0 0 1 )}$ & $(0.771)$ & $(0.466)$ & $(0.786)$ \\
$\mathrm{I}_{\mathrm{r}}$ & 0.9580 & 1.0000 & 0.1725 & 0.1757 & 0.1798 \\
& 0.9700 & 1.0000 & 0.1287 & 0.0982 & 0.0994 \\
& $\mathbf{( 0 . 0 0 1 )}$ & $\mathbf{( 0 . 0 0 1 )}$ & $(0.933)$ & $(0.308)$ & $(0.739)$ \\
$\mathrm{I}_{\text {act }}$ & 0.1473 & 0.1725 & 1.0000 & 0.2501 & 0.2361
\end{tabular}




\begin{tabular}{llllll} 
& 0.1090 & 0.1287 & 1.0000 & 0.2715 & 0.2468 \\
& $(0.792)$ & $(0.912)$ & $\mathbf{( 0 . 0 0 1 )}$ & $\mathbf{( 0 . 0 0 5 )}$ & $\mathbf{( 0 . 0 2 0 )}$ \\
$\mathrm{I}_{\text {pas }}$ & 0.1645 & 0.1757 & 0.2501 & 1.0000 & 0.2326 \\
& 0.0919 & 0.0982 & 0.2715 & 1.0000 & 0.2998 \\
& $(0.482)$ & $(0.311)$ & $\mathbf{( 0 . 0 0 4 )}$ & $\mathbf{( 0 . 0 0 1 )}$ & $\mathbf{( 0 . 0 0 1 )}$ \\
$\mathrm{E}_{\text {pit }}$ & 0.1872 & 0.1798 & 0.2361 & 0.2326 & 1.0000 \\
& 0.0908 & 0.0994 & 0.2468 & 0.2998 & 1.0000 \\
& $(0.790)$ & $(0.734)$ & $\mathbf{( 0 . 0 0 6 )}$ & $\mathbf{( 0 . 0 0 1 )}$ & $\mathbf{( 0 . 0 0 1 )}$ \\
\hline
\end{tabular}

The analyses provide several significant results (see Table 5): PAP parameters are found statistically independent from those of EPR for the given material and welding conditions under all dependence analyses and measures available; this result is consistent with the fact that the mechanism of formation of the passive layer is different in each case: (i) in the EPR test it occurs at a constant potential ( $200 \mathrm{mV}_{\text {SCE}}$ ) being enhanced by the presence of KSCN that acts as an activator in the reactivation process ${ }^{14}$; (ii) in the PAP test, the passive layer formation occurs along the anodic potentiodynamic scan from $V_{\text {oc }}$ to the potential where $l_{\text {act }}$ is reached.

Measures obtained with the PAP test are found dependent upon one another but with a noisy relationship, which could be explained by the fact that the current density along the passive zone is not exactly constant.

Regarding the variables $Q_{r}$ and $I_{r}$ in the EPR test, results confirm the strong relationship between them ${ }^{62,63}$. This last relation was studied in depth and formalized using linear regression and visually-weighted regression ${ }^{64}$ to estimate confidence intervals (Fig. 7). Using the complete empirical database, the regressions show a strong impact of three high $\mathrm{I}_{\mathrm{r}} \mathrm{RSW}$ joints in the results. To weight this influence, the outcome was compared with and without the presence of those three joints. The analysis shows that removing the points, the stability of the linear adjustment increases.
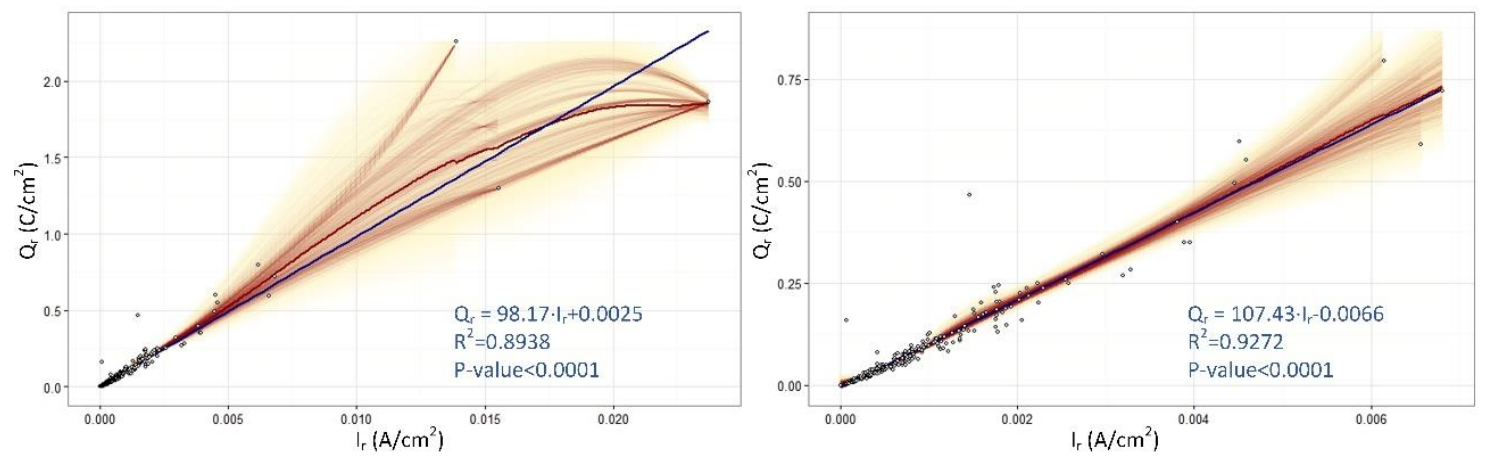

Fig. 7. Experimental relation between $Q_{r}$ and $I_{r}$ using linear regression. Visually-weighted regression has been used to estimate the confidence intervals. Blue lines represent the fitted linear regression model and red lines represent the median bootstrapped regressions. In the left figure the uncertainty of the regression increases as consequence of three high $I_{r}$ RSW joints, removing these points in the right figure increases the good of fitness of the model.

\section{Conclusions}

This work studies the possible relationships among the variables of the PAP and EPR tests performed on RSW joints of AISI 304 SS. The study consists on an in-depth computational 
analysis exploring linear, non-linear and bivariate associations from a 242 sample database. The major conclusions are:

(1) PAP parameters are found statistically independent from those of EPR for the given material and welding conditions under all dependence analysis and measures available; therefore, it is no possible to predict at any level the results of one test from the outcomes of the other, i.e., the DOS, studied by EPR test, cannot be predicted from the pitting corrosion behaviour, studied by PAP test, and vice versa. This conclusion is consistent with the fact that the mechanism of formation of the passive layer is different in each case.

(2) The different parameters obtained with PAP test are found to be significantly associated with each other, but with noisy relationships. This conclusion is consistent with the fact that the current density along the passive zone is not exactly constant, which could be the cause for the noise observed.

(3) The most important parameters obtained from the EPR test, $Q_{r}$ and $I_{r}$, are confirmed to be very related. The explicit formalization of this association is found lin ear and with a high coefficient of determination, which indicates that the linear prediction of one of the measures can be precisely achieved from the other.

\section{Acknowledgements}

The authors would like to thank Dr. L.R. Izquierdo for some advice and comments on this paper. The authors acknowledge support from the Spanish MICINN Project CSD2010-00034 (SimulPast CONSOLIDER-INGENIO 2010).

\section{References}

(1) Hamidinejad, S. M.; Kolahan, F.; Kokabi, a. H. Mater. Des. 2012, 34, 759-767.

(2) Özyürek, D. Mater. Des. 2008, 29 (3), 597-603.

(3) Kianersi, D.; Mostafaei, A.; Mohammadi, J. Metall. Mater. Trans. A Phys. Metall. Mater. Sci. 2014, 45 (10), 4423-4442.

(4) Marashi, P.; Pouranvari, M.; Sanaee, S. M. H.; Abedi, A.; Abootalebi, S. H.; Goodarzi, M. Mater. Sci. Technol. 2008, 24 (12), 1506-1512.

(5) Salvador, C. F.; Antunes, R. A. Corros. Eng. Sci. Technol. 2016, 51 (8), 573580.

(6) Rodrigues, C. A. D.; Pagotto, J. F.; Motheo, A. J.; Tremiliosi-Filho, G. Corros. Eng. Sci. Technol. 2016, 1-8. 
(7) Cheng, F. T.; Lo, K. H.; Man, H. C. Surf. Coatings Technol. 2003, 172 (2-3), 316-321.

(8) Lin, Y. C.; Jiang, Y. Q.; Zhang, X. C.; Deng, J.; Chen, X. M. Mater. Des. 2014, 61, 228-238.

(9) Bai, G.; Lu, S.; Li, D.; Li, Y. Corros. Sci. 2015, 90, 347-358.

(10) Padilha, A. F.; Rios, P. R. ISIJ Int. 2002, 42 (4), 325-337.

(11) Srinivasan, N.; Kain, V.; Birbilis, N.; Mani Krishna, K. V.; Shekhawat, S.; Samajdar, I. Corros. Sci. 2015, 100, 544-555.

(12) Wasnik, D. N.; Dey, G. K.; Kain, V.; Samajdar, I. Scr. Mater. 2003, 49 (2), 135141.

(13) Bühler, H. E.; Gerlach, L.; Greven, O.; Bleck, W. Corros. Sci. 2003, 45 (10), 2325-2336.

(14) De Tiedra, P.; Martín, Ó.; López, M.; San-Juan, M. Corros. Sci. 2011, 53 (4), 1563-1570.

(15) Matula, M.; Hyspecka, L.; Svoboda, M.; Vodarek, V.; Dagbert, C.; Galland, J.; Stonawska, Z.; Tuma, L. Mater. Charact. 2001, 46 (2-3), 203-210.

(16) Bose, A.; De, P. K. Corrosion 1987, 43 (10), 624-631.

(17) Mudali, U. K.; Dayal, R. K.; Gnanamoorthy, J. B.; Rodriguez, P. ISIJ Int. 1996, 36 (7), 799-806.

(18) De Tiedra, P.; Martín, Ó.; López, M. Corros. Sci. 2011, 53 (8), 2670-2675.

(19) Prohaska, M.; Kanduth, H.; Mori, G.; Grill, R.; Tischler, G. Corros. Sci. 2010, 52 (5), 1582-1592.

(20) Č́íhal, V.; Štefec, R. Electrochim. Acta 2001, 46 (24-25), 3867-3877.

(21) Wu, T. F.; Cheng, T. P.; Tsai, W. T. J. Nucl. Mater. 2001, 295 (2-3), 233-243. 
(22) Wu, T. F.; Tsai, W. T. Corros. Sci. 2003, 45 (2), 267-280.

(23) Martín, Ó.; De Tiedra, P.; López, M. Corros. Sci. 2010, 52 (7), 2397-2402.

(24) Jiménez-Come, M. J.; Muñoz, E.; García, R.; Matres, V.; Martín, M. L.; Trujillo, F.; Turias, I. J. Appl. Log. 2012, 10 (4), 291-297.

(25) Jiménez-Come, M. J.; Turias, I. J.; Trujillo, F. J. Mater. Des. 2014, 56, 642-648.

(26) Fernández-Delgado, M.; Cernadas, E.; Barro, S.; Amorim, D.; Amorim Fernández-Delgado, D. J. Mach. Learn. Res. 2014, 15, 3133-3181.

(27) Hastie, T.; Tibshirani, R.; Friedman, J. The Elements of Statistical Learning, 2nd ed.; Springer: New York, NY, 2009.

(28) Santos, S. de S.; Takahashi, D. Y.; Nakata, A.; Fujita, A. Brief. Bioinform. 2013, $15(6), 906-918$.

(29) Kinney, J. B.; Atwal, G. S. Proc. Natl. Acad. Sci. 2014, 111 (9), 3354-3359.

(30) Reshef, D. N.; Reshef, Y. A.; Mitzenmacher, M.; Sabeti, P. C. Proc. Natl. Acad. Sci. U. S. A. 2014, 111 (33), E3362-3.

(31) Simon, N.; Tibshirani, R. Cornell Univ. Libr. 2014, No. 2009, 1-3.

(32) Gorfine, M.; Heller, R.; Heller, Y. 2012.

(33) Reshef, D.; Reshef, Y.; Mitzenmacher, M.; Sabeti, P. Cornell Univ. Libr. 2013, 22.

(34) ASTM A 262-91. Standard practices for detecting susceptibility to intergranular attack in austenitic stainless steels; 1993.

(35) Aslanlar, S. Mater. Des. 2006, 27 (2), 125-131.

(36) Pouranvari, M.; Marashi, S. P. H. Mater. Sci. Technol. 2010, 26 (9), 11371144.

(37) Narimani, N.; Zarei, B.; Pouraliakbar, H.; Khalaj, G. Meas. J. Int. Meas. Confed. 
2015, 62, 97-107.

(38) Saha, D. C.; Ji, C. W.; Park, Y. D. Sci. Technol. Weld. Join. 2015, 20 (8), 708-720.

(39) Pouranvari, M.; Khorramifar, M.; Marashi, S. P. H. Sci. Technol. Weld. Join. 2016, 21 (6), 438-445.

(40) Pereda, M.; Santos, J. I.; Martín, Ó.; Galán, J. M. Sci. Technol. Weld. Join. 2015, $20(8), 679-685$.

(41) Garcia, C.; de Tiedra, M. P.; Blanco, Y.; Martin, O.; Martin, F. Corros. Sci. 2008, 50 (8), 2390-2397.

(42) Vitek, J. M.; David, S. A.; Hinman, C. R. Weld. J. 2003, 82 (1), 10s-17s.

(43) Vitek, J. M.; David, S. A.; Hinman, C. R. Weld. J. 2003, 82 (2), 43s-50s.

(44) Pan, Q. Y.; Huang, W. D.; Song, R. G.; Zhou, Y. H.; Zhang, G. L. Surf. Coat. Technol. 1998, 102 (3), 245-255.

(45) Pujar, M. G.; Dayal, R. K.; Gill, T. P. S.; Malhotra, S. N. J. Mater. Sci. Lett. 1999, 18 (10), 823-826.

(46) Della Rovere, C. A.; Aquino, J. M.; Ribeiro, C. R.; Silva, R.; Alcântara, N. G.; Kuri, S. E. Mater. Des. 2015, 65, 318-327.

(47) Zhang, P.; Liu, Z. Mater. Des. 2016, 100, 254-262.

(48) ASTM G5-94 (Reapproved 1999). Standard reference test method for making potentiostatic and potentiodynamic anodic polarization measurements; 1999.

(49) De Tiedra, P.; Martín, Ó.; San-Juan, M. J. Alloys Compd. 2016, 673, 231-236.

(50) Li, H. B.; Jiang, Z. H.; Feng, H.; Zhang, S. C.; Li, L.; Han, P. D.; Misra, R. D. K.; Li, J. Z. Mater. Des. 2015, 84, 291-299.

(51) Atapour, M.; Sarlak, H.; Esmailzadeh, M. Int. J. Adv. Manuf. Technol. 2016, 83, 721-728. 
(52) Martín, Ó.; De Tiedra, P.; San-Juan, M. Mater. Des. 2015, 87, 266-271.

(53) ASTM Standard G108-92. Standard Test Method for Electrochemical Reactivation (EPR) for Detecting Sensitization of AISI Type 304 and $304 \mathrm{~L}$ Stainless Steels; 1993.

(54) Du, K.-L.; Swamy, M. N. S. Neural Networks and Statistical Learning; Springer: London, 2014.

(55) Smola, A. J.; Schölkopf, B. Stat. Comput. 2004, 14 (3), 199-222.

(56) Breiman, L. Mach. Learn. 2001, 45 (1), 5-32.

(57) Friedman, J. H. Ann. Stat. 2001, 29 (5), 1189-1232.

(58) Székely, G. J.; Rizzo, M. L.; Bakirov, N. K. Ann. Stat. 2007, 35 (6), 2769-2794.

(59) Heller, R.; Heller, Y.; Gorfine, M. Biometrika 2013, 100 (2), 503-510.

(60) Reshef, D.; Reshef, Y.; Finucane, H.; Grossman, S.; Mcvean, G.; Turnbaugh, P.; Lander, E.; Mitzenmacher, M.; Sabeti, P. Sci. Transl. Med. 2011, 334 (6062), 1518-1524.

(61) Chen, Y.; Zeng, Y.; Luo, F.; Yuan, Z. PLoS One 2016, 11 (6), e0157567.

(62) García, C.; Martín, F.; Blanco, Y.; Aparicio, M. L. Corros. Sci. 2010, 52 (11), 3725-3737.

(63) García, C.; Martín, F.; de Tiedra, P.; Blanco, Y.; Ruíz-Roman, J. M.; Aparicio, M. Corros. Sci. 2008, 50 (3), 687-697.

(64) Hsiang, S. M. SSRN Electron. J. 2013, 1-10. 


\section{List of figure captions}

Fig. 1. Micrograph of a longitudinal section of the parent metal, that shows an austenitic structure with $\delta$-ferrite bands clearly oriented in the rolling direction as a result of prior cold work. Electrolytic etching with oxalic acid according to ASTM A 262-91 Practice A ${ }^{26}$.

Fig. 2. Macrograph of a cross-sectioned RSW joint that shows the weld nugget (WN) and the HAZ. Electrolytic etching with oxalic acid according to ASTM A 262-91 Practice A ${ }^{26}$.

Fig. 3. Micrograph of the weld nugget that shows the cast dendritic microstructure of austenite with $\delta$-ferrite in interdendritic regions. Electrolytic etching with oxalic acid according to ASTM A 262-91 Practice A ${ }^{26}$.

Fig. 4. Micrograph of the HAZ, adjacent to the weld nugget (left), which shows: (i) transgranular corrosion (TGC) inside austenitic grains; and (ii) intergranular corrosion (IGC) associated with grain boundaries. Micrograph taken after EPR test.

Fig. 5. PAP curves of: (A) RSW joint obtained with $W T=9$ cycles, $W C=6.42 \mathrm{kA} R M S, E F=1000$ $\mathrm{N}$; and (B) RSW joint obtained with $\mathrm{WT}=11$ cycles, $\mathrm{WC}=6.56 \mathrm{kA} R \mathrm{RMS}, \mathrm{EF}=1000 \mathrm{~N}$.

Fig. 6. EPR curves of: (A) RSW joint obtained with $W T=2$ cycles, $W C=4.06 \mathrm{kA} R M S, E F=1500$ $\mathrm{N}$; and (B) RSW joint obtained with $W T=6$ cycles, $W C=5.64 \mathrm{kA} \mathrm{RMS}, E F=1500 \mathrm{~N}$. $Q_{\mathrm{rA}}$ is the area under $A_{1}-A_{2}-A_{3}$ and $Q_{r B}$ is the area under $B_{1}-B_{2}-B_{3}$. I $I_{r}$ corresponds to $A_{2}$ and $I_{r B}$ corresponds to $B_{2}$.

Fig. 7. Experimental relation between $Q_{r}$ and $I_{r}$ using linear regression. Visually-weighted regression has been used to estimate the confidence intervals. Blue lines represent the fitted linear regression model and red lines represent the median bootstrapped regressions. In the left figure the uncertainty of the regression increases as consequence of three high $\mathrm{I}_{\mathrm{r}} \mathrm{RSW}$ joints, removing these points in the right figure increases the good of fitness of the model. 